bttp://dx.doi.org/10.21707/gs.v11.n03a08

\title{
EFEITOS EM CURTO-PRAZO dAS PRÁTICAS DE EDUCAÇÃo AMBIENTAL NO ProJovem Urbano, João Pessoa-PB
}

\section{Rafael Menezes ${ }^{1 *}$, Antônio Rufino da Silva ${ }^{2}$, Marta Ferreira Lima ${ }^{3}$, Júlio Cézar Luis Pessoa ${ }^{4}$}

\author{
${ }^{1}$ Educador de Ciências da Natureza do ProJovem Urbano João Pessoa. Endereço: R. Carteiro Francisco do Rego Filho, escola municipal Luiza Lima Lobo, \\ bairro Alto do Mateus, 58070-590, João Pessoa/ Paraíba, Brasil. \\ ${ }^{2}$ Educador de Ciências Humanas do ProJovem Urbano Luiza Lima Lobo, João Pessoa. \\ ${ }^{3}$ Educadora de Participação Cidadã do ProJovem Urbano Luiza Lima Lobo, João Pessoa. \\ ${ }^{4}$ Discente do Programa de Pós Graduação em Educação, Anne Sulivan University, Cursista do Aperfeiçoamento EAD UNIRIO "Educação de Jovens e \\ Adultos para a Juventude", Coordenador Geral do ProJovem Urbano João Pessoa. \\ *Autorpara correspondência: menezes_rafael@hotmail.com
}

Recebido em 23 de agosto de 2016. Aceito em 18 de junho de 2017. Publicado em 29 de julho de 2017.

REsumo - A educação ambiental (EA) tem se tornado uma poderosa ferramenta no que tange o ensino-aprendizagem, exercício da cidadania e conscientização da sociedade sobre a sustentabilidade. Esta pesquisa objetivou avaliar os efeitos em curto-prazo das práticas de EA na escola pública Luiza Lima Lobo, ProJovem Urbano (PJU), João Pessoa (Paraíba), Nordeste do Brasil. Durante os seis primeiros meses do PJU, atividades foram desenvolvidas com os alunos, ressaltando a elaboração de painéis, caminhada ecológica no entorno do bairro, composição de uma música/rap sobre a questão ambiental e construção de uma horta orgânica. De modo geral, o feedback das práticas desenvolvidas foi amplamente positivo, evidenciando as habilidades dos alunos em tarefas manuais e a concepção pelos temas ambientais. Iniciativas como estas são cruciais a incitar ações coletivas dos jovens quanto aos problemas ambientais ocorrentes na comunidade, contribuindo assim ao desenvolvimento socioeconômico local.

Palavras-chave: Educação de Jovens e Adultos; Educação Inclusiva; Atividades Pedagógicas.

\section{Short-term effects of environmental education practices in the ProJovem Urbano program, João Pessoa-} PB.

Aвstract - Environmental education (EE) has become a powerful tool regarding to teaching-learning process, citizenship exercise and human awareness over sustainability. This research aimed to evaluate the short-term effects of the EE practices at Luiza Lima Lobo School, ProJovem Urbano (PJU) program, João Pessoa city (Paraíba State), Northeastern from Brazil. Over the first six months of the PJU, activities were developed with the students, highlighting banner construction, ecological walk around the neighboorhood, composition of a rap-like music about environmental issues, and the making of an organic vegetable garden. Overall, the feedback of the developed practices was largely positive, evidencing both the students' skills on hand-made tasks and the conception about the environmental themes. Initiatives like these are critical to incite collective actions of the teens regarding the occurring environmental problems in the community, contributing to the local socioeconomic development.

Keywords: Teens and Adults Education; Inclusive Education; Pedagogical Activities.

\section{Efectos a corto plazo de las prácticas de educación ambiental en el Projoven Urbano, João Pessoa-PB}

RESUMEN - La educación ambiental (EA) se ha convertido en una herramienta poderosa cuando se trata de la enseñanza y el aprendizaje, ejercicio dela ciudadanía y concientización de la sociedad sobre la sostenibilidad. Esta investigación 
tuvo como objetivo evaluar los efectos a corto plazo de las prácticas de EA en la escuela pública Luiza Lima Lobo, ProJoven Urbano (PJU), João Pessoa (Paraíba), Noreste de Brasil. Durante los primeros seis meses del PJU, las actividades se desarrollaron con los estudiantes, destacándose la elaboración de paneles, caminata ecológica alrededor del barrio, composición de una canción/rap acerca de la cuestión ambientaly construcción de una huerta orgánica. En general, el feedback de las prácticas desarrolladas fue ampliamente positivo, tornando evidentes las habilidades de los estudiantes en tareas manuales y la concepción por los temas ambientales. Iniciativas como éstas son cruciales para fomentar acciones colectivas de los jóvenes sobre los problemas ambientales que se producen en la comunidad, contribuyendo así al desarrollo socioeconómico local.

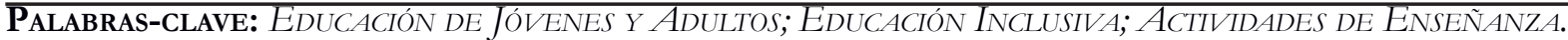

\section{INTRODUÇÃO}

A crise ambiental contemporânea tem forçado a sociedade, cada vez mais, a buscar alternativas que mitiguem os impactos negativos provenientes das ações antrópicas (Foladori 1999). Essa nova tendência, conhecida como desenvolvimento sustentável (ou sustentabilidade), consiste em um modelo econômico cujas atividades sejam “ecologicamente sustentáveis, socialmente justas e economicamente viáveis” (Primavesi 2008). Não obstante, coadunar estas três esferas (social, econômico e ambiental) tem sido o grande desafio do século 21(Hall e Vredenburg 2003).

Neste contexto, a Educação Ambiental (EA), compreendida como um processo de construção crítica e moral sobre as questões ambientais (Medina 2001), tem se tornado uma poderosa ferramenta para alcançar tal paradigma (Reid 2011). A EA é um instrumento educacional regido por lei que preconiza que a mesma “[...] seja desenvolvida como prática educativa integrada, contínua e permanente em todos os níveis e modalidades do ensino formal (Art. 10, Lei 9795/99)". Logo, a EA está diretamente relacionada ao exercício da cidadania e dos direitos humanos (Jacobi 2003), uma vez que a reconstrução da identidade, baseado nos hábitos e costumes, é constantemente trabalhada (Dias 2004).

Frente à crise contemporânea, dados apontam que 49\% dos jovens brasileiros ( $\approx 25$ anos) não possuem o Ensino Fundamental completo (IBGE 2010). Diante deste cenário, a região Nordeste detém os maiores percentuais, com destaque para os estados de Alagoas, Paraíba e Piauí (IBGE 2010). A reverter essa realidade, os programas de inclusão social destinado a educação de jovens e adultos (EJA) têm sido determinantes à elevação da escolaridade e mercado de trabalho no País. Nos últimos 10 anos, os avanços foram notoriamente vistos, com uma ascensão de cerca 15\% dos jovens ingressando ao Ensino Médio e, muitos deles, conquistando o primeiro emprego (IBGE 2010).

O ProJovem Urbano (PJU) representa um marco histórico para a política de educação inclusiva no Brasil (Andrade et al. 2009). Instituído em 2005, o PJU é um plano do governo federal destinado a jovens entre 18 a 29 anos que saibam ler e escrever, mas que não concluíram o ensino fundamental (Salgado e Amaral 2008). O PJU abrange três dimensões, a saber: Formação Básica (Português, Matemática, Inglês, Ciências Humanas e Ciências da Natureza), Qualificação Profissional e Participação Cidadã. Esses dois últimos estão relacionados à capacitação dos jovens ao mercado de trabalho e atuação sociopolítica em sua comunidade, respectivamente. Ao término dos 18 meses, além da conclusão do Ensino Fundamental, o jovem terá uma formação profissional inicial. A qualificação profissional oferece subsídios teórico-práticos para os discentes ampliarem seus conhecimentos e suas possibilidades em relação ao mundo do trabalho, como também atua no fomento a aquisição de habilidades 
e competências profissionais. Além disso, os alunos aprendem questões gerais e pressupostos básicos específicos voltados ao desenvolvimento inicial de uma profissão, de acordo com o Arco Ocupacional do Núcleo (e.g vestuário, educação, construção e reparos).

Compreender como a EA auxilia a percepção do jovem como cidadão transformador do ambiente é de suma importância no entendimento de sua efetividade nos programas de inclusão social. Embora seja necessário um tempo relativamente longo para avaliar, com precisão, os reais efeitos da adoção das práticas de EA (e.g. Silva et al. 2015), respostas em curto-prazo podem ser rapidamente mensuráveis.

Neste trabalho, o objetivo foi avaliar os efeitos em curto-prazo da adoção de práticas pedagógicas de educação ambiental desenvolvidas com alunos do núcleo Luiza Lima Lobo, ProJovem Urbano, João Pessoa-PB. Pretendeu-se também descrever como as atividades foram realizadas a fim de servirem como instrumentos de veiculação por outros educadores.

\section{Metodologia}

A escola Luiza Lima Lobo localiza-se no conjunto Ivan Bichara, bairro Alto do Mateus, cidade de João Pessoa (Paraíba), na região Nordeste do Brasil. Ela compõe uma das 95 escolas municipais de Ensino Fundamental da rede pública de João Pessoa. Além do ProJovem Urbano, a escola possui também o ensino de alfabetização na Educação de Jovens e Adultos (EJA). Em sua edição atual (2015-2016), o PJU contempla 20 escolas públicas (chamadas pelo programa de "núcleos") distribuídas na grande João Pessoa.

As atividades de educação ambiental foram trabalhadas na escola e no seu entorno durante os seis primeiros meses de vigência do programa (Unidades Formativas I e II). No PJU, a cada três meses conclui-se uma Unidade Formativa (UF), análogo aos períodos bimestrais do ensino regular. Como se trata de um programa que prima pela construção do conhecimento integrado, as atividades de EA desenvolvidas foram planejadas e executadas interdisciplinarmente entre os educadores do núcleo. A avaliação destas práticas foi realizada de forma qualitativa, percebendo a reação, dedicação e entusiasmo dos alunos em suas execuções, bem como a assimilação pelos temas abordados durante as práticas. Abaixo segue a descrição de cada atividade:

\section{Construção do painel ecológico (05/06/2015)}

Em comemoração ao Dia do Meio Ambiente, alunos e educadores construíram através de "recorte e cole" um grande esboço de uma árvore (papel madeira) que foi afixada na parede. Em seguida, cada aluno escreveu, em um arquétipo de uma folha (papel reciclado), cinco ações simples que ajudam a reduzir o desperdício de água. Finalmente, os alunos colaram essas folhas nos galhos da árvore com sentido pedagógico que suas ações sejam "frutificadas" para as próximas gerações. Cabe ressaltar que um vídeo sobre reciclagem de materiais e reutilização da água foi previamente exposto a fim de introduzir o tema. O objetivo principal da prática foi o despertar de como os nossos costumes podem degradar o meio ambiente.

\section{Caminhada ecológica no entorno da escola (20/08/2015)}

Educadores e alunos realizaram uma caminhada ecológica na adjacência da escola no intuito de discutir 
temas relacionados ao meio ambiente. Os alunos levaram cadernos e lápis para anotações das diversas formas de impactos ambientais presentes em seu bairro. Ao término da caminhada, os educadores se reuniram com os alunos em uma praça próxima a escola para dialogar como aqueles tipos de degradações poderiam acarretar em riscos a saúde humana.

\section{Elaboração de uma música (rap) sobre a questão ambiental (24/08/2015)}

Os alunos foram estimulados a desenvolver trechos de músicas (estilo rap) com a temática da degradação ambiental. A turma foi dividida em grupos de 4 a 5 alunos, onde cada grupo construiu uma estrofe da música. A atividade foi fruto da síntese integradora, parte estruturante do PJU, cujo tema integrador era "os hábitos culturais da minha comunidade respeitam a natureza?". O foco central desta prática foi avaliar os talentos dos jovens quanto à construção de rimas musicais, visto que é uma característica marcante nas culturas de periferias.

\section{Construção de hortas orgânicas (21/09/2015)}

Em homenagem ao Dia da Árvore, alunos do PJU, com auxílio dos educadores, construíram hortas orgânicas verticais a partir de material reciclado. Garrafas PET, linha de nylon, terra vegetal e sementes de hortaliças (e.g. salsinha, coentro, alface e cebolinha) foram os materiais usados para a confecção da horta. Tal prática objetivou elucidar as questões ambientais relacionadas à reutilização de materiais, bem como tratar sobre os benefícios dos alimentos orgânicos (sem uso de agrotóxicos) a saúde humana. Foi reforçado também que todas essas hortaliças serão usadas na própria merenda deles.

\section{REsultados}

\section{Construção do painel ecológico}

As principais ações mencionadas pelos alunos foram relacionadas à economia da água nas atividades diárias de higiene ("desligar o chuveiro ao se ensaboar durante o banho", "fechar a torneira enquanto escovar os dentes") e reutilização da água nos serviços domésticos ("usar a água da lavagem de roupa para aguar as plantas"). Foram registradas também, em menor freqüência, ações relacionadas ao racionamento de energia ("desligar a lâmpada ao sair do quarto", "desligar a televisão quando sair da sala"). A Figura 1 ilustra o produto final da atividade prática (i.e. painel) confeccionado pelos alunos com auxílio dos educadores.

\section{Caminhada ecológica no entorno da escola}

Durante a roda de conversa na Praça das Mangueiras (Figura2) o tipo de impacto mais evidente pelos alunos foi o descarte de resíduos sólidos em locais inadequados ("lixo em terrenos baldios e nas ruas"). Em adição, eles diagnosticaram a presença de efluentes domésticos em áreas públicas ("esgoto escoando nas valas das ruas"), poluição sonora ("som alto de carro nas praças") e depredação de espaços públicos ("piso quebrado da praça”). 
Figura 1 - Painel de ações ecológicas (afixado na parede) construído por todos.

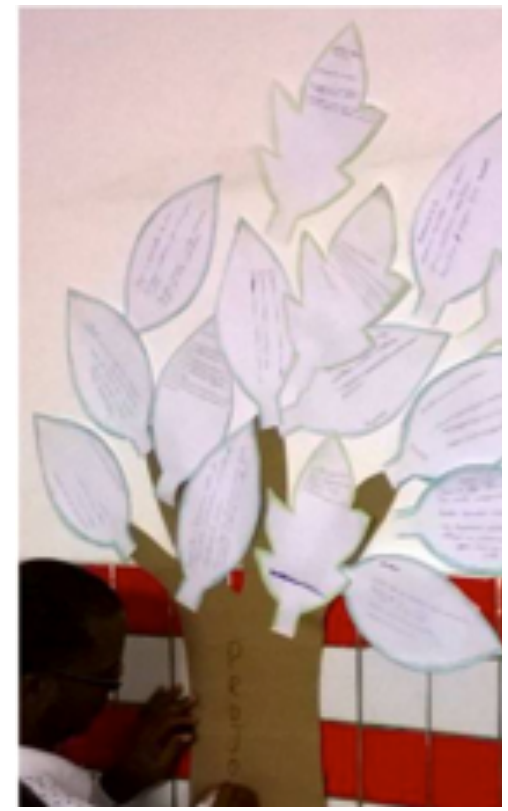

Figura 2 - Roda de conversa entre educadores e alunos PJU sobre as conseqüências dos impactos ambientais observados no bairro.

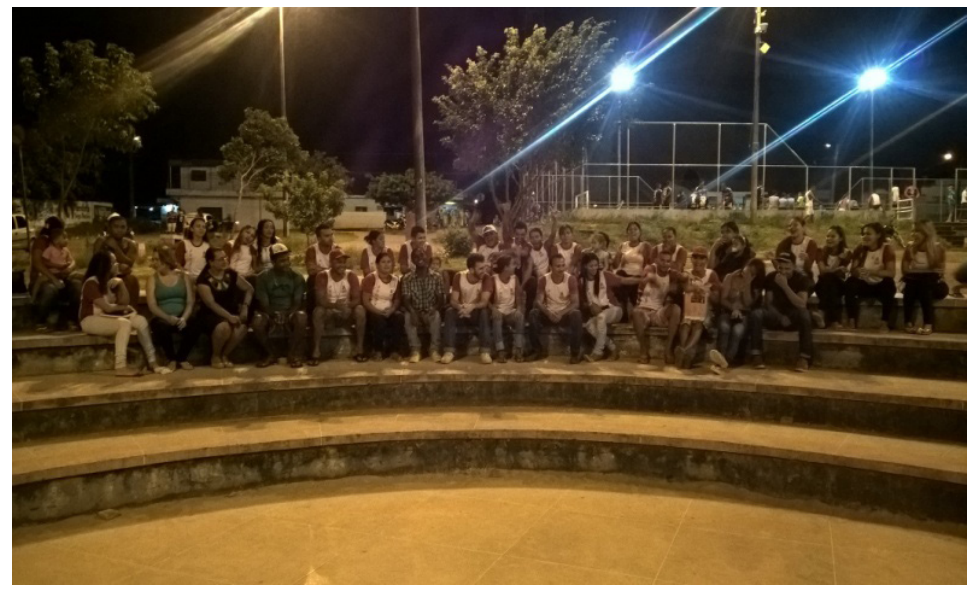

Elaboração de uma música (rap) sobre a questão ambiental

Rap 1: "Vamos cuidar, vamos preservar, pra a natureza não acabar, as nossas atitudes devemos repensar. Escuta aí galera no som que eu vou mandar, vou falar do ambiente que tá precisando melhorar; a nossa natureza tá ficando maltratada, por causa das pessoas que não querem saber de nada! Eu tô falando sério, e não é brincadeira, porque onde passamos só vemos lixo e muita sujeira. Esse é o nosso som, e tâmo aqui mandando vê, para que um dia nossos filhos, a natureza conhecer!"

Rap 2: "Muitos vêem e não falam nada, passam por cima achando que é calçada, quando o problema está se agravando, sem notarem o que está se passando. Preservar é preciso, educar é viver, se conscientizar para um novo amanhecer! Meio ambiente: preservando o presente, garantindo o futuro... meio ambiente: preservando o presente, garantindo o futuro".

\section{Construção de hortas orgânicas}


Durante a construção da horta orgânica os alunos se mostraram muito habilidosos em tarefas manuais, mesmo com pouca experiência na confecção de hortas. Nesse primeiro momento, foi construído apenas uma horta, composta de 4 garrafas, porém foi apenas um "projeto piloto". O objetivo é dar continuidade a essa prática para que em um futuro próximo os alunos possam consumir as hortaliças provenientes do trabalho em equipe.

\section{Discussão}

Nos últimos anos, uma crescente atenção tem sido dada aos programas de inclusão social (e.g. ProJovem e EJA) a fim de amenizar a árdua realidade dos jovens brasileiros de baixa renda, - a falta de escolarização e desemprego. Em João Pessoa/Paraíba, cerca de 40.000 jovens não possuem o Ensino Fundamental completo. Apesar desse número está sendo gradativamente amortizado em virtude desses programas, muito ainda há o que ser feito por esses jovens que vivem as margens da sociedade.

É neste cenário de desafios que surge a importante função do educador, - integrar o conhecimento empírico dos jovens aos conteúdos abordados em sala de aula. Dessa maneira, a interdisciplinaridade constitui um eficaz instrumento pedagógico na construção do conhecimento (Alves et al. 2004), proporcionando uma visão holística e desfragmentada das disciplinas. Em adição, as atividades extraclasses se tornam essenciais à consolidação do conhecimento teórico-científico (Borges e Lima 2007). Durante estes seis meses, pretendeu-se sempre aliar esses dois elementos (interdisciplinaridade e atividade extraclasses) nas práticas de educação ambiental.

De modo geral, o feedback das práticas de EA foi amplamente positivo. Por exemplo, a construção do painel foi interessante para enxergar como os jovens estão realmente preocupados com a racionalização da água. Além das diversas ações relacionadas à economia e reutilização da água, ressalva-se a percepção sobre a questão energética ("desligar a lâmpada ao sair do quarto", “desligar a televisão quando sair da sala”), evidenciando um olhar interdisciplinar desses jovens sobre a crise hídrica atual. A respeito da caminhada, os alunos conseguiram perceber diversos tipos de impactos ambientais, em que alguns deles são incomuns. Por exemplo, o impacto da poluição sonora ("som alto de carro nas praças"), mesmo não sendo tão divulgado pelas mídias, tem efeitos severos à saúde humana, sobretudo relacionada a problemas auditivos.

Quanto à construção da música, os alunos conseguiram realizar um excelente trabalho, ressaltando suas habilidades como compositores, especialmente relacionados às rimas, e suas ideias sobre a temática ambiental. Alguns elementos interessantes podem ser destacados na letra das músicas, como a relação homem-natureza ("nossa natureza tá ficando maltratada, por causa das pessoas que não querem saber de nada"), a necessidade da preservação nos dias atuais ("preservar é preciso, educar é viver”) e a responsabilidade ambiental para as futuras gerações ("para que um dia nossos filhos, a natureza conhecer!"). A horta orgânica, por sua vez, também obteve uma resposta satisfatória, onde muitos alunos ficaram surpresos como o próprio "lixo" (garrafas pet, linha de nylon, corda) pode ser transformado em artefatos rentáveis. Além disso, a prática provocou a discussão entre alunos e educadores no que se refere a como nossa saúde está sendo acometida pelas comidas industrializadas, bem como sobre a importância de ações simples na melhoria dos nossos hábitos alimentares.

Atividades de educação ambiental fazem com que os alunos coloquem em prática os conhecimentos teórico-científicos vistos em sala de aula, demonstrando assim muitas de suas habilidades, como artesanato e composição musical. Assim, tais práticas contribuem significativamente para redução da evasão dos jovens 
do ambiente escolar, uma característica ainda muito marcante nos programas de inclusão social (Abramovay 2015). No caso específico do núcleo Luiza Lima Lobo, diversas ações têm sido realizadas para assegurar a permanência desses jovens (e.g. torneio de jogos esportivos, gincana, projeto Sexta Cine, passeios), sendo uma delas justamente aumentar a freqüência de atividades práticas.

Recentemente, pesquisas envolvendo educação ambiental no Ensino de Jovens e Adultos/ProJovem tem sido desenvolvidas tanto no âmbito de percepção discente quanto docente.Por exemplo, Rocha e Oliveira (2014) avaliaram o entendimento dos educadores PJU de Gravataí (Rio Grande do Sul - RS) sobre como a educação ambiental está inserida em suas disciplinas. Tais resultados foram preocupantes, visto que alguns educadores, mesmo de áreas como Ciências da Natureza, relataram que o meio ambiente consistia apenas do ambiente físico, dos animais e plantas, desconsiderando o papel do homem como agente integrador e transformador. Similarmente, Chaves e Farias (2005) reportaram que educadores das redes privadas e públicas de Canoas (RS) utilizavam a EA de maneira momentânea nas práticas pedagógicas, muitas vezes de forma desarticulada com outras disciplinas ou conteúdos abordados.

Em Borborema/Paraíba, Calado et al. (2014) realizaram questionários a fim de avaliar a concepção dos alunos acerca de diversos temas ambientais (e.g. Meio Ambiente, Educação Ambiental, Resíduos Sólidos e Coletiva Seletiva). Os autores concluíram que, embora sejam temas contemporâneos, a visão dos estudantes ainda é muito incipiente sobre as questões ambientais. Tais estudos reforçam a urgente necessidade da incorporação da EA no ambiente escolar como iniciativa de conscientização ambiental à população, tais como as reportadas nesta pesquisa. Distintamente aos trabalhos anteriores, uma recente pesquisa de longo-prazo registrou uma infinidade de efeitos positivos na transformação psicossocial dos jovens, abarcando princípios da equidade social, solidariedade, respeito e compromisso com a sustentabilidade (Silva et al. 2015).

\section{Conclusão}

Portanto, as práticas de EA desenvolvidas com os alunos PJU Luiza Lima Lobo representam apenas uma semente que foi plantada para o "despertar" dos jovens como agentes transformadores do meio em que vivem e, conseqüentemente, o seu reconhecimento como protagonistas locais. No entanto, para que as ações sejam realmente efetivas, tais práticas devem ser mantidas tanto pelos educadores quanto pelos alunos. Logo, efeitos positivos em longo-prazo serão colhidos por todos, contribuindo assim ao desenvolvimento socioeconômico local.

\section{Agradecimentos}

Os autores agradecem aos funcionários da escola e a todos os alunos do núcleo Luiza Lima Lobo pelo empenho na adoção das práticas de educação ambiental. Ademais, o autor principal agradece em especial a Bartolomeu Israel de Souza pela valiosa contribuição no manuscrito (tradução do resumo em espanhol). 


\section{REFERÊNCIAS}

Abramovay M. 2015. Juventudes na escola, sentidos e buscas: Por que frequentam? Miriam Abramovay, Mary Garcia Castro, Júlio Jacobo Waiselfisz (eds.). Brasília-DF: Flacso-Brasil, OEI, MEC.

Alves RF, Brasileiro MDCE, Brito SMDO. 2004. Interdisciplinaridade: um conceito em construção. Episteme, 19(2):139-148.

Andrade ER, Esteves LCG, Oliveira ECD. 2009. Composição social e percursos escolares dos sujeitos do ProJovem: novos/velhos desafios para o campo da educação de jovens e adultos. Aberto Brasília, 22(82):73-89.

Borges, RMR e Lima VDR. 2007. Tendências contemporâneas do ensino de Biologia no Brasil. Revista Electrónica de Enseñanza de lãs Ciencias, 6(1):165-175.

Calado KA, Batista JB, Camarotti JB. 2014. Um diagnóstico preliminar sobre a educação ambiental: Programa Projovem adolescente de Borborema-PB. Gaia Scientia, 8(1):392-398.

Chaves AL e Farias M.E. 2005. Meio ambiente, escola e a formação dos professores. Ciência \& Educação, 11(1):63-71.

Dias GF. 2004. Educação Ambiental: princípios e práticas. 9ª Ed. São Paulo: Gaia.

Foladori G. 1999. O capitalismo e a crise ambiental. Revista Raízes, 18(19):31-36.

Hall J e Vredenburg H. 2003. The challenges of innovating for sustainable development.MIT Sloan Management Review, 45(1):61.

IBGE. Censo demográfico 2010. Disponível em http://www.ibge.gov.br. Acesso em 03 de Março de 2016.

Jacobi P. 2003. Educação ambiental, cidadania e sustentabilidade. Cadernos de Pesquisa, 118(3):189-205.

Medina NMA. 2001. Formação dos professores em Educação Ambiental. In: Panorama da educação ambiental no ensino fundamental / Secretaria de Educação Fundamental - Brasília: MEC.

Primavesi AM. 2008. Agroecologia e manejo do solo. Revista Agriculturas, 5(3):7-10.

Reid DDA. 2011. Environment and sustainable development. Availableat SSRN 1981400.

Rocha D e Oliveira CT. 2014. Educação ambiental no programa ProJovem Urbano de Gravataí/RS: premissas para uma compreensão da educação de jovens e adultos no contexto escolar. Revista Eletrônica do Mestrado em Educação Ambiental, 31(2):207-222.

Salgado MC e Amaral A. 2008. Manual do educador: orientações gerais. Programa Nacional de Inclusão de Jovens-Projovem Urbano:Brasília.

Silva WG, Higuchi MIG, Farias MSM. 2015. Educação ambiental na formação psicossocial dos jovens. Ciência \& Educação, 21(4):1031-1047. 